\title{
A new species of Characidium (Characiformes: Crenuchidae) from coastal basins in the Atlantic Rainforest of eastern Brazil, with phylogenetic and phylogeographic insights into the Characidium alipioi species group
}

\author{
Evandro Malanski ${ }^{1,2,5}$, Luisa Maria Sarmento-Soares ${ }^{1,3,6}$, \\ Ana Cecilia Gomes Silva-Malanski ${ }^{2,5}$, Maridiesse Morais Lopes ${ }^{3}$, \\ Leonardo Ferreira da Silva Ingenito ${ }^{1,4}$ and Paulo Andreas Buckup ${ }^{2}$
}

A new species of Characidium from southeastern Brazil is described based on morphological and molecular evidence from specimens collected between the rio Jucuruçu and rio Doce basins. The new species belongs to a group of species within Characidium with an unscaled area in the isthmus and is distinguished from these species, except C. alipioi, C. fasciatum, C. hasemani, and C. kamakan, by the greater distance (greater than 10\% SL) and presence of 5-7 scales between the anus and the anal fin, and presence of 14 series of scales around the caudal peduncle. The species is distinguished from C. alipioi by having 4 series of scales above the lateral line ( $v s .5$ series) and greater distance between the anus and the anal fin; from C. fasciatum and C. kamakan, by the smaller body depth at the dorsal-fin origin, at the anal-fin origin, and at the caudal peduncle; from C. hasemani, by the short distances between the tip of the snout and the pelvic fin, the tip of the snout and the anal fin, and the tip of the snout and the tip of anal fin. The new species forms a presumably monophyletic group with C. alipioi and C. kamakan.

Keywords: Bahia, DNA barcode, Espírito Santo, Rapids, South American darter.

Uma nova espécie de Characidium do sudeste do Brasil é descrita com base em evidências morfológicas e moleculares provenientes de exemplares coletados entre as bacias dos rios Jucuruçu e Doce. A nova espécie pertence a um grupo de espécies de Characidium com área desprovida de escamas no ístmo e difere dessas espécies, exceto C. alipioi, $C$. fasciatum, C. hasemani e C. kamakan, pela grande distância (maior que $10 \%$ do comprimento padrão, CP) e presença de 5-7 escamas entre o ânus e a nadadeira anal, e pela presença de 14 séries de escamas em torno do pedúnculo caudal. A espécie difere de $C$. alipioi pela presença de 4 séries de escamas acima da linha lateral (vs. 5 séries) e maior distância entre o ânus e a nadadeira anal; de C. fasciatum e C. kamakan, pela menor altura do corpo na origem da nadadeira dorsal, na origem da nadadeira anal, e no pedúnculo caudal; de C. hasemani, pela menor distância entre a ponta do focinho e a nadadeira pélvica, a ponta do focinho e a nadadeira anal, e a ponta do focinho e a ponta da nadadeira anal. A nova espécie forma um grupo presumidamente monofilético com C. alipioi e C. kamakan.

Palavras-chave: Bahia, Código de barra de DNA, Corredeiras, Espírito Santo, Mocinha.

\section{Introduction}

Characidium is the most widespread and species-rich genus of crenuchid fishes. Currently, 69 valid species of Characidium are known, 13 of which were described during the last four years (Fricke et al., 2019). Monophyly of the group is supported by the presence of a dark spot on base of median caudal-fin rays, a feature secondarily lost in some species (Buckup, 1993a; Buckup, 1993b; Melo, Buckup, 2002). Most species inhabit fast flowing streams

\footnotetext{
${ }^{1}$ Instituto Nacional da Mata Atlântica, INMA, Av. José Ruschi 4, 29650-000 Santa Teresa, ES, Brazil. (EM) evanmal@gmail.com, Dhttps:// orcid.org/0000-0002-4315-8540 (corresponding author); (LMSS) sarmento.soares@gmail.com, Dhttps://orcid.org/0000-0002-8621-1794; (LFSI) leo.ingenito@gmail.com, @ittps://orcid.org/0000-0002-5506-0620

${ }^{2}$ Museu Nacional, Universidade Federal do Rio de Janeiro, Quinta da Boa Vista, 20940-040 Rio de Janeiro, RJ, Brazil. (ACGSM) aceciliagomes@gmail.com, @https://orcid.org/0000-0002-3052-963X; (PAB) buckup@acd.ufrj.br, @https://orcid.org/0000-0002-1156-3226 ${ }^{3}$ Programa de Pós-Graduação em Biologia Animal, Centro de Ciências Humanas e Naturais, Universidade Federal do Espírito Santo, Prédio Bárbara Weinberg, Campus de Goiabeiras, 29043-900 Vitória, ES, Brazil. maridiessemorais@gmail.com, @ohttps://orcid. org/0000-0001-5103-1446

${ }^{4}$ Programa de Pós-Graduação em Biodiversidade Tropical, Centro Universitário Norte do Espírito Santo, Universidade Federal do Espírito Santo, BR-101 Norte km 60, 29932-540 São Mateus, ES, Brazil.

${ }^{5}$ Base Oceanográfica, Universidade Federal do Espírito Santo, ES-010 km 16, 565, 29199-970 Aracruz, ES, Brazil.

${ }^{6}$ Universidade Estadual de Feira de Santana, Avenida Transnordestina s/n, Novo Horizonte, 44036-900 Feira de Santana, BA, Brazil.
} 
with rocky or sandy substrates. The genus has a broad distribution in South America, ranging from Panama, in Central America, to northeastern Argentina in southern South America (Fricke et al., 2019).

Here we describe a new species of Characidium from the Northeastern Mata Atlântica Ecorregion in Eastern Brazil (Abell et al., 2008). Seven species of Characidium were previously reported from this area: Characidium bahiense Almeida, 1971, Characidium clistenesi Melo, Espíndola, 2016, Characidium deludens Zanata, Camelier, 2015, Characidium helmeri Zanata, Sarmento-Soares, Martins-Pinheiro, 2015, Characidium kamakan Zanata, Camelier, 2015, Characidium samurai Zanata, Camelier, 2014, and Characidium timbuiense Travassos, 1946. The fish species diversity of this Ecoregion is still poorly known, as suggested by the fact that five of these species of Characidium were described in the last three years. The present description underscores the lack of taxonomic knowledge in the region.

\section{Material and Methods}

Specimens analysed are deposited in the ichthyological collection of the Coleção Zoológica do Norte Capixaba (CZNC) of the Centro Universitário Norte do Espírito Santo, Universidade Federal do Espírito Santo, the Instituto Nacional da Mata Atlântica (formelly Museu de Biologia Professor Mello Leitão - MBML), the Museu Nacional, Universidade Federal do Rio de Janeiro (MNRJ), and the Museu de Zoologia da Universidade de São Paulo (MZUSP). The comparative data for Characidium fasciatum Reinhardt, 1867, also includes information obtained from the type specimens available from Buckup (Buckup, 1992).

Meristic and morphometric data were obtained from the left side of specimens, unless some damage was verified, with the use of a binocular stereomicroscope and a digital caliper with $0.01 \mathrm{~mm}$ precision. Counts and measurements were performed according to protocols previously established for crenuchid fishes (Buckup, 1993b; Melo, Oyakawa, 2015). We also counted number of scales in the series extending between anus and anal-fin base; the first scale of this series is usually small, pointy, and located just posterior to the anus, and the scale located immediately anterior to the anal-fin origin is usually U-shaped and surrounds the first anal-fin ray. In the text, all counts are followed by their frequency in parentheses; asterisk indicates the value for the holotype. We use the term "unscaled" to describe the absence of scales in the isthmus and chest area, instead of the term "naked", which has been used elsewhere.

Specimens were cleared and stained according to the method proposed by Taylor, Van Dyke (1985). Specimens were radiographed with the use of a Faxitron MX-20 Cabinet X-ray System. Cleared-and-stained (CS) specimens and radiographic images were used for skeletal counts, and confirmation of supernumerary anal-fin elements.
The four anterior-most vertebral centra modified into the Weberian apparatus were included in vertebral counts. The description of osteological characteristics followed the terminology from Weitzman (1962).

Species delimitation was based on an integrative approach, where anatomic and color patterns were used in conjunction with DNA barcoding methods (Hebert et al., 2003). Muscular tissue from selected specimens, including sympatric and selected outgroup species, were used for DNA extraction following the salting out method (Miller et al., 1988). DNA quality was verified with standard agarose gel electrophoresis. DNA concentration was measured using a NanoDrop ND-2000 spectrophotometer. Partial sequences of the Cytochrome Oxidase Subunit I (COI) gene were amplified with Polymerase Chain Reaction (PCR) using primers FishF1 (5'-TCA ACC AAC CAC AAA GAC ATT GGC AC-3') and FishR1 (5'-TAG ACT TCT GGG TGG CCA AAG AAT CA-3') (Ward et al., 2005), and FishF6 (5'-TGT AAA ACG ACG GCC AGT ACY AAY CAC AAA GAY ATT GGC A-3') and FishR7 (5'-CAG GAA ACA GCT ATG ACC TAR ACT TCT GGR TGD CCR AAG AAY CA-3') which included M13 sequencing primer sequences appended (Jennings et al., 2019). The PCR protocol used the following thermal cycle: denaturation at $94^{\circ} \mathrm{C} / 30 \mathrm{~s}$, primer hybridization at $50^{\circ} \mathrm{C} / 45 \mathrm{~s}$, and nucleotide extension at $72^{\circ} \mathrm{C} / 45 \mathrm{~s}$; this sequence was repeated 35 times in a loop, and the reaction was terminated with $72^{\circ} \mathrm{C} / 10 \mathrm{~min}$ and $4{ }^{\circ} \mathrm{C} / 5 \mathrm{~min}$. Quality of amplified products was verified with $1 \%$ agarose-gel electrophoresis. PCR products were purified using Exo-SAP (Handy et al., 2011) or PEG (Jennings, 2016; Lis, 1980), and bidirectionally sequenced following an automated Sanger method (Sanger et al., 1977; Otto et al., 2008), where a BigDyeTM Terminator v3.1 Cycle Sequencing kit (Applied Biosystems) was used for labeling, purified again with ethanol precipitation and loaded on an automatic sequencer ABI3730xl (Applied Biosystems) at Fundação Oswaldo Cruz - FIOCRUZ.

The resulting chromatograms were aligned to a reference sequence using the Geneious v9.1 software and manually edited to ensure codon alignment and fine tune base calls. The sequences and associated data, including geospatial coordinates, sequence data, trace files, and primer details are available in the Barcode of Life Data Systems (BOLD Systems, http://boldsystems.org/; Ratnasingham, Hebert (2007)). Sample details are listed in Tab. 1, along with GenBank Accession codes.

The degree of genetic divergence among samples was evaluated from genetic distances using a maximum likelihood tree. The evolution model selected for calculation of distances was based on the on the jModelTest software (Posada, 2008), and the best model $(\mathrm{HKY}+\mathrm{G})$ was then used to generate a maximum likelihood tree through MEGA 7.0.26 software (Kumar et al., 2016). Specimens with less than $2 \%$ of genetic distance were considered conspecific following DNA barcoding standards for fish (Pereira et al., 2013). 
Tab. 1. List of specimens used to obtain molecular data in this study. Sample ID refers to the DNA Extract Collection of the Laboratório de Pesquisa em Biodiversidade Molecular, Museu Nacional (MNLM), which are also used to record specimen data in BoldSystems (http://www.boldsystems.org/). Voucher code refers to the whole-organism catalog numbers, and Specimen/Tissue core refers to tissue catalog number in the respective ichthyologic collection. Specimens from the paratype series are indicated by an asterisk.

\begin{tabular}{|c|c|c|c|c|c|c|}
\hline Species & Drainage & Sample ID & Voucher code & Specimen/ Tissue code & BoldSystems Process ID & GenBank Accession \\
\hline \multirow{3}{*}{ Characidium alipioi } & Macaé & MNLM 3004 & MNRJ 39301 & MNTI5390 & MNRJ1080-18 & MH667901 \\
\hline & Macaé & MNLM 3007 & MNRJ 39301 & MNTI5393 & MNRJ1081-18 & MH667874 \\
\hline & São João & MNLM 5462 & MNRJ 42780 & MNTI9341 & MNRJ1082-18 & MH667868 \\
\hline \multirow{36}{*}{ Characidium cricarense } & Doce & MNLM 5314 & MNRJ $41832 *$ & MNTI9001 & MNRJ1044-18 & MH667899 \\
\hline & Doce & MNLM 5315 & MNRJ 41832* & MNTI9002 & MNRJ1045-18 & MH667878 \\
\hline & Doce & MNLM 5316 & MNRJ 41832* & MNTI9003 & MNRJ1046-18 & MH667864 \\
\hline & Doce & MNLM 5397 & MNRJ 41832* & MNTI9004 & MNRJ1047-18 & MH667863 \\
\hline & Doce & MNLM 5398 & MNRJ 41832* & MNTI9005 & MNRJ1048-18 & MH667862 \\
\hline & Doce & MNLM 5399 & MNRJ $41832 *$ & MNTI9006 & MNRJ1049-18 & MH667876 \\
\hline & Doce & MNLM 5400 & MNRJ 41832* & MNTI9007 & MNRJ1050-18 & MH667867 \\
\hline & Doce & MNLM 5401 & MNRJ 41832* & MNTI9008 & MNRJ1051-18 & MH667887 \\
\hline & Doce & MNLM 5402 & MNRJ 41832* & MNTI9009 & MNRJ1052-18 & MH667884 \\
\hline & Doce & MNLM 5487 & MNRJ $41832 *$ & MNTI9010 & MNRJ1053-18 & MH667885 \\
\hline & Doce & MNLM 5491 & MNRJ 41879 & MNTI9043 & MNRJ1054-18 & MH667872 \\
\hline & Doce & MNLM 5492 & MNRJ 41879 & MNTI9044 & MNRJ1055-18 & MH667860 \\
\hline & Doce & MNLM 5493 & MNRJ 41879 & MNTI9045 & MNRJ1056-18 & MH667888 \\
\hline & Doce & MNLM 5494 & MNRJ 41879 & MNTI9046 & MNRJ1057-18 & MH667870 \\
\hline & Doce & MNLM 5495 & MNRJ 41879 & MNTI9047 & MNRJ1058-18 & MH667882 \\
\hline & Itaúnas & MNLM 8069 & MBML 4808 & AC16 & MNRJ1059-18 & MH667900 \\
\hline & Itaúnas & MNLM 8072 & MBML 7227 & AI41 & MNRJ1060-18 & MH667861 \\
\hline & Itaúnas & MNLM 8171 & CZNC 874 & MNTI12536 & MNRJ1069-18 & MH667890 \\
\hline & Itaúnas & MNLM 8172 & CZNC 874 & MNTI12537 & MNRJ1070-18 & MH667865 \\
\hline & Itaúnas & MNLM 8262 & MNRJ 50962* & MNTI12872 & MNRJ1072-18 & MH667894 \\
\hline & Itaúnas & MNLM 8263 & MNRJ 50962* & MNTI12873 & MNRJ1073-18 & MH667879 \\
\hline & Jucuruçu & MNLM 8081 & MBML 7501 & AJ83 & MNRJ1061-18 & MH667881 \\
\hline & Jucuruçu & MNLM 8082 & MBML 7501 & AJ84 & MNRJ1062-18 & MH667891 \\
\hline & Jucuruçu & MNLM 8083 & MBML 7501 & AJ85 & MNRJ1063-18 & MH667883 \\
\hline & Jucuruçu & MNLM 8085 & MBML 7508 & AJ98 & MNRJ1064-18 & MH667893 \\
\hline & São Mateus & MNLM 8162 & CZNC 1506 & MNTI12527 & MNRJ1065-18 & MH667902 \\
\hline & São Mateus & MNLM 8163 & CZNC 1477 & MNTI12528 & MNRJ1066-18 & MH667898 \\
\hline & São Mateus & MNLM 8164 & CZNC 1477 & MNTI12529 & MNRJ1067-18 & MH667869 \\
\hline & São Mateus & MNLM 8168 & CZNC 1443 & MNTI12533 & MNRJ1068-18 & MH667895 \\
\hline & São Mateus & MNLM 8176 & CZNC 1593 & MNTI12541 & MNRJ1071-18 & MH667866 \\
\hline & São Mateus & MNLM 8268 & MNRJ 50973* & MNTI12897 & MNRJ1074-18 & MH667886 \\
\hline & São Mateus & MNLM 8269 & MNRJ 50973* & MNTI12898 & MNRJ1075-18 & MH667896 \\
\hline & São Mateus & MNLM 8491 & MNRJ 37635 & MNTI3705 & MNRJ1076-18 & MH667880 \\
\hline & São Mateus & MNLM 8492 & MNRJ 37635 & MNTI3706 & MNRJ1077-18 & MH667889 \\
\hline & São Mateus & MNLM 8493 & MNRJ 37635 & MNTI3707 & MNRJ1078-18 & MH667877 \\
\hline & São Mateus & MNLM 8494 & MNRJ 37635 & MNTI3709 & MNRJ1079-18 & MH667897 \\
\hline Characidium litorale & São João & MNLM 7660 & MNRJ 47087 & MNTI11592 & MNRJ1086-18 & MH667873 \\
\hline Characidium pterostictum & Tramandaí & MNLM 4901 & MNRJ 41094 & MNTI7614 & MNRJ1084-18 & MH667871 \\
\hline Characidium timbuiense & Reis Magos & MNLM 5403 & MNRJ 41900 & MNTI9077 & MNRJ1085-18 & MH667892 \\
\hline Characidium vidali & Guapimirim & MNLM 2043 & MNRJ 40284 & MNTI6206 & MNRJ1083-18 & MH667875 \\
\hline
\end{tabular}




\section{Results}

\section{Characidium cricarense, new species}

urn:1sid:zoobank.org:act:C2DB8329-F89A-4A25-968EC6F52896E386

Fig. 1, Tabs. 1-2

Holotype. MNRJ 51282, 49.0 mm SL, Brazil, Espírito Santo, São Mateus municipality, São Mateus basin, rio Cricaré at Cachoeira do Inferno rapids, $18^{\circ} 42^{\prime} 24.5^{\prime \prime} \mathrm{S} 40^{\circ} 16^{\prime} 7.2^{\prime \prime} \mathrm{W}$, $18 \mathrm{~m}$ above sea level, 15 Aug 2017, P.A. Buckup, D.F. Moraes Junior, E. Malanski \& V. de Britto.

Paratypes. All from Brazil, Espírito Santo. Rio Itaúnas basin: MNRJ 50962, 46 (2 for DNA, 2 CS), 41.3-47.7 mm SL (13, 41.3-47.7 mm SL), Pedro Canário municipality, rio Itaúnas at Cachoeira da Mata waterfall, north of Floresta do Sul, 18 12'11.6”'S 404'36.3”'W, $17 \mathrm{~m}$ above sea level, 15 Aug 2017, P.A. Buckup, D.F. Moraes Junior, E. Malanski \& V. de Britto. Rio São Mateus basin: MNRJ 50973, 16 (2 for DNA, 2 CS), 39.2-48.0 mm SL (4, 39.2-48.0 mm SL), MBML 13549, 5, 42.0-48.8 mm SL, collected with holotype. Rio Doce basin: MNRJ 41832, 33 (10 for DNA), 40.7-55.9 mm SL (9, 40.7-55.9 mm SL), Santa Teresa municipality, rio Santa Maria do Rio Doce at Cachoeira do Rúdio waterfall, 1950'5"S 4041'12'W, $159 \mathrm{~m}$ above sea level, 5 Oct 2013, J.R. Gomes, E. Neuhaus \& C.C.D. Quijada.

Non-types. Locality data has been abbreviated to include only the municipality, state abbreviation, and name of main river. All from Brazil, grouped according to hydrographic basins from north to south. Rio Jucuruçu basin: MBML 7501 (3 for DNA), 12, 22.2-31.2 mm SL, Palmópolis, MG, rio do Prado; MBML 7508 (1 for DNA), 2, 39.339.7 mm SL, Palmópolis, MG, córrego Paulino Laranjeira; MBML 12879, 1, $30.3 \mathrm{~mm}$ SL, Itamaraju, BA, tributary of rio Jucuruçu. Rio Itanhém-Alcobaça basin: MBML 3846, 5, 33.7-36.7 mm SL, Medeiros Neto, BA, córrego do Medeiros Neto. Rio Mucuri basin: MNRJ 38334, 8, 29.2-50.2 mm SL, Teófilo Otoni, MG, rio Todos os Santos; MNRJ 38335, 32, 23.3-39.3 mm SL, Teófilo Otoni, MG, rio Todos os Santos; MNRJ 38336, 11, 33.4-40.5 mm SL, Teófilo Otoni, MG, rio Todos os Santos; MZUSP 54818, 25, 18.4-34.4 mm SL, Teófilo Otoni, MG, riacho São Pedro; MZUSP 54821, 8, 25.0-38.6 mm SL, Teófilo Otoni, MG, rio Todos os Santos. Rio Itaúnas basin: CZNC 874 (2 for DNA), 41, 38.8-44.0 mm SL, Montanha, ES, rio Itaúnas; CZNC 1376, 57, 28.4-40.7 mm SL, Pedro Canário, ES, rio Itaúnas; MBML 4782, 1, 31.4 mm SL, Conceição da Barra, ES, córrego Grande; MBML 4807, 4, 22.7-25.2 mm SL, Conceição da Barra, ES, córrego Grande; MBML 4808, 6 (1 for DNA), 22.2-23.1 mm SL, Pedro Canário, ES, córrego Douradão; MBML 4830, 2, 29.6 mm SL, Conceição da
Barra, ES, córrego Grande; MBML 7217, 4, $34.7 \mathrm{~mm}$ SL, Pinheiros, ES, córrego Santo Antônio; MBML 7223, 19, 22.8-31.9 mm SL, Pinheiros, ES, tributary of córrego Santo Antônio; MBML 7227, 1 (1 for DNA), $25.8 \mathrm{~mm}$ SL, Pinheiros, ES, córrego Santo Antônio; MBML 7235, 2, 31.0-32.1 mm SL, Pinheiros, ES, córrego do Veado; MBML 7248, 2, 32.8-38.5 mm SL, Pinheiros, ES, córrego São Roque; MBML 7261, 1, 22.1 mm SL, Pinheiros, ES, córrego do Veado; MNRJ 37635, 41 (4 for DNA), 21.3$40.8 \mathrm{~mm}$ SL, Barra de São Francisco, ES, rio Itaúnas; MZUSP 54817, 80, 18.5-39.6 mm SL, Pinheiros, ES, rio do Sul. Rio São Mateus basin: CZNC 167, 6, 32.4-34.4 mm SL, São Mateus, ES, rio Cricaré; CZNC 1047, 6, 39.141.2 mm SL, São Mateus, ES, rio Cricaré; CZNC 1389, 8 , 39.6-39.8 mm SL, Ecoporanga, ES, rio Dois de Setembro; CZNC 1443, 45 (1 for DNA), 37.4-40.0 mm SL, Vila Pavão, ES, córrego da Rapadura; CZNC 1467, 9, 45.4 mm SL, Vila Pavão, ES, córrego Alecrim; CZNC 1477 (2 for DNA), 17, 36.4-48.7 mm SL, Barra de São Francisco, ES, rio Cricaré; CZNC 1506 (1 for DNA), 20, 36.8-47.0 mm SL, Água Doce do Norte, ES, rio Preto; CZNC 1531, 11, $34.3 \mathrm{~mm}$ SL, Ecoporanga, ES, rio Cotaxé; CZNC 1535, 6, 34.3$36.8 \mathrm{~mm}$ SL, Ataléia, ES, rio do Norte; CZNC 1545, 10, 26.4-47.7 mm SL, Ecoporanga, ES, rio Dois de Setembro; CZNC 1556, 50, 32.1-34.1 mm SL, Ataléia, ES, rio Paraju; CZNC 1576, 1, 37.4 mm SL, Ecoporanga, ES, ribeirão Santa Rita; CZNC 1593 (1 for DNA), 37, 33.6-34.5 mm SL, Ecoporanga, ES, córrego Lajeado; MBML 3480, 1, $40.9 \mathrm{~mm}$ SL, Água Doce do Norte, ES, córrego Água Doce; MBML 3484, 15, 28.0-43.2 mm SL, Água Doce do Norte, ES, rio Preto; MNRJ 50845, 1, $34.8 \mathrm{~mm} \mathrm{SL}$, Boa Esperança, ES, rio Cotaxé; MZUSP 54820, 5, 36.0$37.2 \mathrm{~mm}$ SL, Boa Esperança, ES, rio Braço Norte. Rio Doce basin: MBML 4369, 6, 31.4-43.7 mm SL, Santa Teresa, ES, rio Santa Maria do Rio Doce; MBML 4371, 15, 29.1-40.1 mm SL, Santa Teresa, ES, rio Santa Maria do Rio Doce; MBML 4381, 2, 32.4-46.6 mm SL, Santa Teresa, ES, rio Santa Maria do Rio Doce; MBML 4388, 6, 38.7-53.0 mm SL, Santa Teresa, ES, rio Santa Maria do Rio Doce; MBML 4403, 1, $34.2 \mathrm{~mm}$ SL, Santa Teresa, ES, rio Santa Maria do Rio Doce; MBML 4422, 3, 33.5$33.9 \mathrm{~mm}$ SL, Santa Teresa, ES, rio Santa Maria do Rio Doce; MBML 4456, 1, $44.5 \mathrm{~mm}$ SL, Santa Teresa, ES, tributary of rio Santa Maria do Rio Doce; MBML 7636, 10, 44.6-52.7 mm SL, Santa Teresa, ES, rio Santa Maria do Rio Doce; MNRJ 22420, 11, 38.7-55.6 mm SL, Santa Teresa, ES, rio Santa Maria; MNRJ 36190, 10, 23.9-42.6 mm SL, Laranja da Terra, ES, ribeirão Lagoa; MNRJ 37625, 5, 30.0-39.2 mm SL, Baixo Guandu, ES, rio Mutum; MNRJ 37730, 8, 27.7-34.3 mm SL, Águia Branca, ES, rio Braço Sul; MNRJ 37737, 6, 32.6-50.5 mm SL, Águia Branca, ES, córrego Água Calma; MNRJ 41879, 7 (5 for DNA), 34.9-49.2 mm SL, Santa Teresa, ES, rio Santa Maria do Rio Doce; MNRJ 50842, 55, 36.1-46.7 mm SL, Santa Teresa, ES, rio Santa Maria do Rio Doce at cachoeira do Rúdio. 
Diagnosis. The new species is included in a group of species of Characidium with an unscaled area in the isthmus (vs. isthmus scaled in C. bahiense, C. bimaculatum Fowler, 1941, C. boehlkei Géry, 1972, C. borellii (Boulenger, 1895), C. caucanum Eigenmann, 1912, C. chupa Schultz, 1944, C. clistenesi, C. deludens, C. etheostoma Cope, 1872, C. etzeli Zarske, Géry, 2001, C. geryi (Zarske, 1997), C. heinianum Zarske, Géry, 2001, C. heirmostigmata Graça, Pavanelli, 2008, C. interruptum Pellegrin, 1909, C. lagosantense Travassos, 1947, C. lanei Travassos, 1967, C. laterale (Boulenger, 1895), C. litorale Leitão, Buckup, 2014, C. longum Taphorn, Montaña, Buckup, 2006, C. marshi Breder, 1925, C. mirim Netto-Ferreira, Birindelli, Buckup, 2013, C. nana Mendonça, Netto-Ferreira, 2015, C. nupelia Graça, Pavanelli, Buckup, 2008, C. occidentale Buckup, Reis, 1997, C. orientale Buckup, Reis, 1997, C. papachibe Peixoto, Wosiacki, 2013, C. pellucidum Eigenmann, 1909, C. phoxocephalum Eigenmann, 1912, C. pteroides Eigenmann, 1909, C. rachovii Regan, 1913, C. roesseli Géry, 1965, C. samurai, C. sanctjohanni Dahl, 1960, C. satoi Melo, Oyakawa, 2015, C. schindleri Zarske, Géry, 2001, C. serrano Buckup, Reis, 1997, C. steindachneri Cope, 1878, C. stigmosum Melo, Buckup, 2002, C. tapuia Zanata, Ramos, Oliveira-Silva, 2018, C. tenue (Cope, 1894), C. vestigipinne Buckup, Hahn, 2000, C. xanthopterum Silveira, Langeani, da Graça, Pavanelli, Buckup, 2008, C. xavante Graça, Pavanelli, Buckup, 2008, and C. zebra Eigenmann, 1909). Within this group of species, Characidium cricarense is distinguished from other species, except C. alipioi Travassos, 1955, C. fasciatum, C. hasemani Steindachner, 1915, and C. kamakan, by the presence of 5-7 scales and distance between the anus and the anal-fin greater than $10 \%$ SL (vs. 2-4 scales and distance shorter than $10 \% \mathrm{SL}$ in C. boavistae Steindachner, 1915, C. grajahuense Travassos, 1944, C. helmeri, C. japuhybense Travassos, 1949, C. lauroi Travassos, 1949, C. oiticicai Travassos, 1967, C. pterostictum Gomes, 1947, C. schubarti Travassos, 1955, C. summum Zanata, Ohara, 2015, C. timbuiense, C. travassosi Melo, Buckup, Oyakawa, 2016, and C. vidali Travassos, 1967), and 14 series of scales around the caudal peduncle (vs. 12 or less series of scales around caudal peduncle in C. amaila Lujan, Agudelo-Zamora, Taphorn, Booth, López-Fernández, 2013, C. brevirostre Pellegrin, 1909, C. crandellii Steindachner, 1915, C. declivirostre Steindachner, 1915, C. gomesi Travassos, 1956, C. macrolepidotum (Peters, 1868), C. purpuratum Steindachner, 1882 and C. sterbai (Zarske, 1997)). Characidium cricarense is distinguished from C. alipioi by having 4 series of scales above the lateral line ( $v s .5$ series) and a greater distance between the anus and the anal fin (11.4-15.5 vs. 10.1-11.1\% SL); from C. fasciatum and $C$. kamakan by the smaller body depth at the dorsalfin origin (16.3-20.0 vs. 20.1-23.1 and 20.6-21.8\% SL, respectively), at the anal fin origin (13.0-15.5 vs. 16.1-17.2 and $16.6-17.8 \% \mathrm{SL}$, respectively), and at the caudal peduncle (8.8-10.5 vs. 11.6-12.5 and 12.0-12.9\% SL, respectively); from $C$. hasemani by the short distances between the tip of the snout and the pelvic fin (46.1-50.2 vs. 53.2-55.6\% SL), the tip of the snout and the anal fin (72.1-76.4 vs. 76.4-79.9\% SL), and the tip of the snout and the tip of anal fin (87.5-92.2 vs. $94.4-100.6 \% \mathrm{SL}$ ).

Description. In Tab. 2, morphometric data is summarized for holotype and paratypes. Characidium cricarense has elongate, fusiform body (Fig. 1). Greatest body depth at dorsal-fin origin. Dorsal profile in lateral view convex from snout to origin of dorsal fin; convex, posteriorly slanted at base of dorsal fin, almost straight between base of dorsal fin and adipose fin; posteriorly slanted at base of adipose fin, almost straight between adipose fin and caudal fin. Ventral profile in lateral view slightly concave between lower lip and base of pectoral fin, slightly straight from pectoral base to anal-fin origin, straight and slightly slanted at base of anal fin, straight below caudal peduncle. Pelvic-fin origin at vertical line about two scales posterior to dorsal-fin origin. Adipose fin at vertical line about two and a half scales posterior to anal-fin origin.

Snout directed downwards, dorsally convex in lateral view (Fig. 1a). Mouth subterminal, aligned with or lower to ventral margin of orbit. Posterior tip of maxilla not reaching level of anterior margin of orbit. Orbit oval, slightly elongate along axis from tip of snout to parietal bone; margin of eye free. Nares widely separated; distance between nares larger than distance between posterior naris and eye. Margin of anterior naris expanded, forming circular rim; posterior naris with expanded margin on its anterior-most portion. Parietal branch of supraorbital laterosensory canal present, reaching parietal bone in larger specimens; frontal branch of supraorbital laterosensory canal present. Fontanel reduced, limited anteriorly by frontals, laterally by parietals and posteriorly by supraoccipital bones.

Premaxillary teeth 6(3) in single series; teeth decreasing gradually in size posteriorly, unicuspid or tricuspid. An anomalous specimen with premaxillae fused, with 13 teeth in total. Dentary teeth in two rows; outer series of dentary teeth $8(2)$ or $9(2)$ unicuspid or triscuspid with small medial and lateral cuspids; teeth decreasing gradually in size posteriorly; inner series of dentary teeth with several tiny conical teeth on edge of replacement tooth trench. Maxillary teeth absent. Ectopterygoid teeth present, in single row, conical, unicuspid. Mesopterygoid teeth absent. Branchiostegal rays 4(1), 5(2) or 6 including one as vestigial (1); 3(1), 4(2) or 4 including one as vestigial (1) attached to anterior ceratohyal. Gill rakers on first arch 11(3) or 12(1).

Scales cycloid; parallel radii present on posterior field. Lateral series of scales 35(4), 36(25*), or 37(3), all perforated by lateral-line canal. Scales above lateral line $4(32 *)$. Scales below lateral line $4(32 *)$. Scales around caudal peduncle $14(32 *)$. Pre-dorsal scale series arranged in single, regular row; scales in pre-dorsal series 8(1), 9(7), 10(17), 11(6*), or 12(1). Scales between anus and origin of anal fin 5(5), 6(23*), or 7(4). Isthmus without scales; chest scaled (Fig. 1d). 
Tab. 2. Morphometric data for Characidium cricarense n. sp. based on holotype (MNRJ 51282) and paratypes (MNRJ 41832 , $\mathrm{n}=9$; MNRJ 50962, n=13; MNRJ 50973, n=4; MBML 13549, n=5). Distances are based on landmarks described in Melo, Oyakawa (2015); ' $n$ ' is the number of specimens examined; SD is the standard deviation.

\begin{tabular}{|c|c|c|c|c|c|c|}
\hline Distances & Character & Holotype & $\mathrm{n}$ & Range & Mean & SD \\
\hline $1-2 v$ & Total length (mm) & 58.02 & 32 & $47.29-64.80$ & 53.8 & - \\
\hline $1-3$ & Standard length $(\mathrm{mm})$ & 49.00 & 32 & $39.23-55.92$ & 45.16 & - \\
\hline \multicolumn{7}{|c|}{ Percentage of standard length } \\
\hline $1-4$ & Head length & 20.41 & 32 & $19.01-24.05$ & 21.63 & 1.24 \\
\hline $1-5$ & Prepectoral distance & 19.23 & 32 & $19.10-22.40$ & 20.40 & 0.90 \\
\hline $5-6$ & Pectoral-fin height & 18.17 & 32 & $16.60-20.49$ & 18.17 & 0.91 \\
\hline $1-7$ & Predorsal distance & 41.48 & 32 & $41.48-44.66$ & 43.29 & 0.82 \\
\hline $7-8$ & Dorsal-fin height & 17.23 & 32 & $15.13-20.33$ & 17.39 & 1.36 \\
\hline $7-9$ & Dorsal-fin base & 15.21 & 32 & $11.85-15.84$ & 13.89 & 0.96 \\
\hline $1-10$ & Prepelvic distance & 47.44 & 32 & $46.14-50.16$ & 48.02 & 1.12 \\
\hline $10-11$ & Pelvic-fin height & 11.37 & 32 & $10.28-13.62$ & 11.50 & 0.78 \\
\hline $1-13$ & Preanal distance & 73.22 & 32 & $72.06-76.37$ & 74.15 & 1.12 \\
\hline $1-15$ & Anal-apex distance & 89.30 & 32 & $87.48-92.21$ & 89.60 & 1.09 \\
\hline $12-13$ & Anus to anal-fin distance & 12.78 & 32 & $11.36-15.55$ & 13.20 & 1.09 \\
\hline $13-14$ & Anal-fin height & 13.62 & 32 & $10.73-13.79$ & 12.85 & 0.69 \\
\hline $13-16$ & Anal-fin base & 7.41 & 32 & $5.77-8.37$ & 7.03 & 0.65 \\
\hline $17-18$ & Adipose-fin height & 5.96 & 32 & $4.09-6.65$ & 5.57 & 0.61 \\
\hline $16-3$ & Peduncle length & 19.84 & 32 & $17.18-21.94$ & 19.80 & 1.13 \\
\hline $7-7$ & Body depth at dorsal-fin origin & 17.62 & 32 & $16.33-20.03$ & 18.26 & 0.97 \\
\hline 13-13' & Body depth at anal-fin origin & 14.86 & 32 & $13.03-15.46$ & 13.89 & 0.64 \\
\hline 19-19’ & Body depth at caudal peduncle & 10.02 & 32 & $8.78-10.54$ & 9.83 & 0.40 \\
\hline 5 (left-right) & Body width & 10.43 & 32 & $8.72-11.99$ & 10.25 & 0.72 \\
\hline \multicolumn{7}{|c|}{ Percentage of head length } \\
\hline $1-20$ & Snout length & 28.80 & 32 & $24.47-30.93$ & 28.25 & 1.42 \\
\hline $1-23$ & Snout-maxillary tip & 24.70 & 32 & $22.00-27.27$ & 25.04 & 1.44 \\
\hline $24-20$ & Anterior naris-orbit & 14.00 & 32 & $11.63-15.56$ & 13.61 & 0.87 \\
\hline $25-20$ & Posterior naris-orbit & 7.20 & 32 & $5.73-8.28$ & 6.72 & 0.64 \\
\hline $22-26$ & Cheek & 14.10 & 32 & $11.38-15.24$ & 13.04 & 0.85 \\
\hline $20-21$ & Orbital diameter & 25.50 & 32 & $25.11-29.00$ & 26.84 & 0.98 \\
\hline 27 (left-right) & Interorbital diameter & 27.90 & 32 & $23.24-31.12$ & 27.57 & 1.9 \\
\hline
\end{tabular}

Dorsal-fin rays i,9(1), ii,8(3), ii,9(27*), or ii,10(1). Adipose fin present $\left(32^{*}\right)$. Pectoral-fin rays iii, $8, \mathrm{i}(3)$, iii, $9(4)$, iii, $9, \mathrm{i}\left(15^{*}\right)$, iii,10(9), or iii,10,i(1). Pelvic-fin rays i,7,i(23*), or i,8(9). Anal-fin rays i,6(2), i,7(3), ii,6(5), or ii, $7(21 *)$; adnate rays on last pterygiophore of anal fin $1\left(21^{*}\right)$, or $2(8)$. Principal caudal-fin rays i,9,7,i(1) or i,9,8,i(12*).

Postcleithrum I absent; and postcleithrum II and postcleithrum III present in pectoral girdle; cleithrum with posteriorly directed process at region immediately below ventral tip of supracleithrum. Precaudal vertebrae 19(2) or 20(6); total vertebrae 33(1), 34(3), 36(3) or 37(1). Supraneurals $4(3), 5(3)$ or 6(1). Upper procurrent rays $7(1), 8(6)$ or $9(2)$; lower procurrent rays 6(7), 7(1) or 8(1). Epurals 3(3).

Coloration in alcohol. Background color yellowish (Fig. 1). Black longitudinal stripe about half scale thick extending from tip of snout to base of caudal fin. Body with 8 to 13 triangular bars, wider dorsally, thinner ventrally; bars from opposite sides united across dorsal midline by a corresponding series of dorsal blotches; bars located posteriorly to pelvic fin extending to ventral surface of body. Humeral blotch partially merged into first bar. Dark spot present at base of middle caudal fin rays. All fins mostly hyaline, with scattered chromatophores along rays forming bands of variable intensity. Dorsal fin with three bands; main (intermediate) band dark, not reaching anterior-most margin of fin. In smaller specimens, caudal-fin pigmentation restricted to some scattered chromatophores at outer lobes, ontogenetically developing into conspicuous incomplete B-shaped pattern in larger specimens, formed by a posterior extension of the lateral stripe and diagonal bands across the dorsal and ventral portions of fin. Pectoral, pelvic and anal fins with dark, diffuse distal bands. 

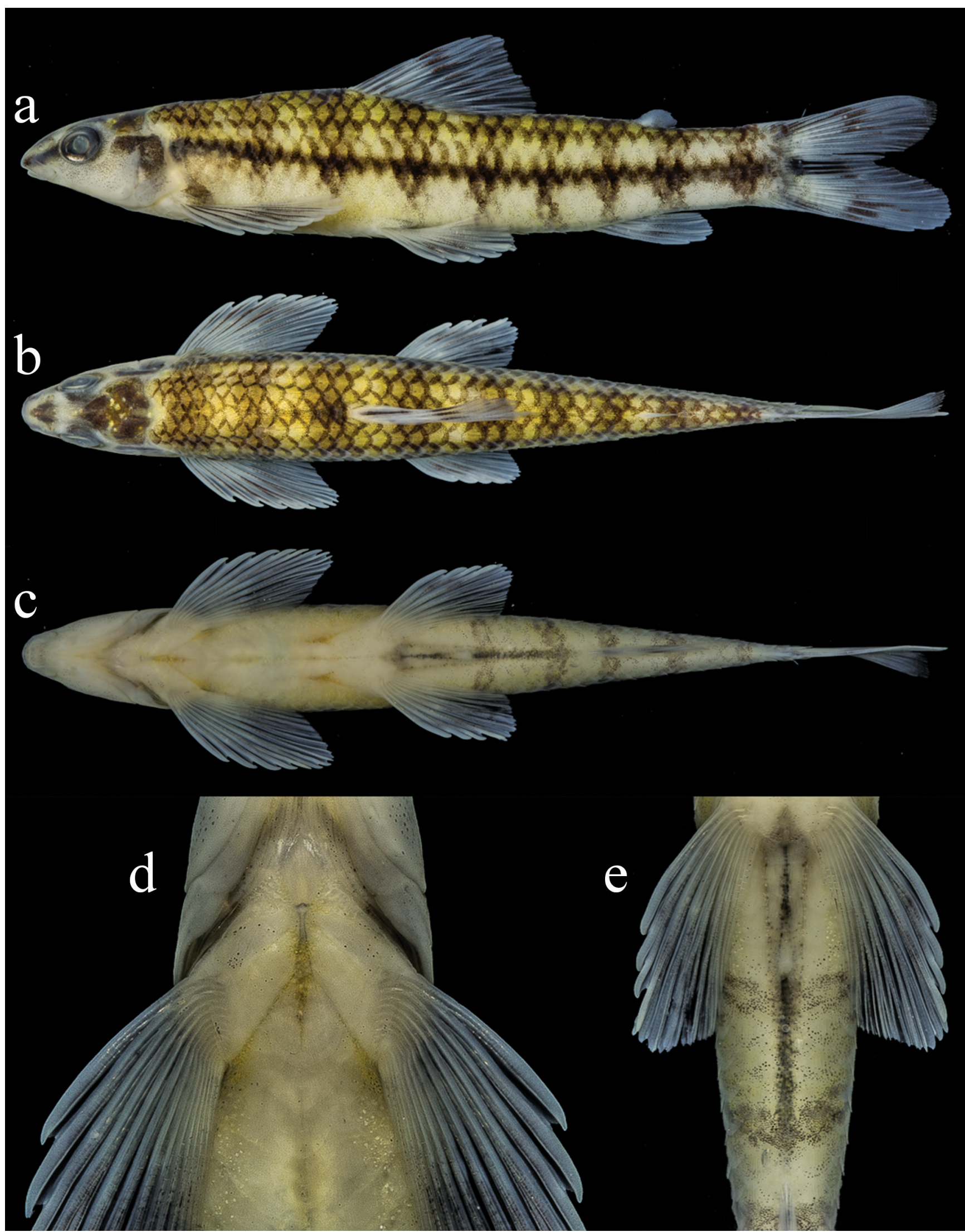

Fig. 1. Characidium cricarense, new species. MNRJ 50962, $45.8 \mathrm{~mm}$ SL, paratype in a. lateral, b. dorsal, and c. ventral views; rio Itaúnas, rio Itaúnas basin. In details: d. the unscaled isthmus, the scaled pectoral base, and e. the area between the anus and the anal-fin. 
Color in life. Slightly translucent body, with olive-greenish or light-brownish background color on head and dorsum. Silvery background below lateral stripe. Dark chromatophore patterns as described for specimens preserved in ethanol.

Sexual dimorphism. No hooks on fins or other sexually dimorphic features were observed externally on the examined specimens.

Molecular delimitation. DNA barcodes based on the amplified 656bp (base pairs) partial sequence of COI mitochondrial gene were generated for a total of 36 specimens of Characidium cricarense (Tab. 1), encompassing specimens from the Jucuruçu basin (4 individuals), Itaúnas basin (6 individuals), São Mateus basin (11 individual), and Doce basin (15 individuals). All samples exhibit less than $2 \%$ of genetic divergence, which is the usually accepted upper limit of conspecific similarity (Pereira et al., 2013). Characidium cricarence received the Barcode Index Number (BIN) BOLD:ACI3743 through the BoldSystems automated algorithm (Ratnasingham, Hebert, 2013).

The genetic distance of Characidium cricarense from other congeneric species analyzed were 6\% divergence from C. alipioi specimens from Macaé (MNLM 3004, MNLM 3007) and São João (MNLM 5462) basins; 11\% divergence from C. timbuiense specimen from Reis Magos basin (MNLM 5403); 12\% divergence from C. vidali specimen from Guanabara basin (MNLM 2043) (Fig. 2). The specimen used as outgroup, C. litorale from São João basin (MNLM 7660), is 23\% divergent from the remaining species in the analysis.

Geographical distribution. Characidium cricarense is known from the southern portion of Bahia State, northern portion of Espírito Santo State, and eastern portion of Minas Gerais State, where it is known from the rio Jucuruçu, rio Itanhém-Alcobaça, rio Mucuri, rio Itaúnas, and rio São Mateus drainages, extending to the rio Doce drainage in the central portion of the Espírito Santo State, Brazil (Fig. 3). The rivers from the northern portion of the distribution are within the coastal tablelands of the Barreiras sedimentary formation. These coastal tablelands correspond to a region of mild relief, with elevations usually not surpassing $150 \mathrm{~m}$ above sea level, formed by Cenozoic sediments, well-seen along the border between the States of Espírito Santo and Bahia (Sarmento-Soares, Martins-Pinheiro, 2013). On the right bank of the rio Doce, C. cricarense reaches the lower slopes of the Serra de Santa Teresa. According to a global biogeographic regionalization of freshwater systems, this geographic distribution belongs to the Northeastern Mata Atlântica ecoregion (Abell et al., 2008).

Ecological notes. Characidium cricarense inhabits lowland stretches of rivers, usually below $200 \mathrm{~m}$ above sea level, except in the Mucuri drainage, where it has been found in the upper rio Todos os Santos, above the city of Teófilo Otoni at about $500 \mathrm{~m}$ above sea level (G. M. Mattox, pers. comm.), and in the Jucuruçu drainage, in tributaries around the city of Palmópolis at about 300 and $600 \mathrm{~m}$ above sea level. Based on our field observations, individuals of this species usually occupy the edge of turbulent, moderately fast flowing rivers and streams (Fig. 4). Specimens aggregate along stretches less than $1.5 \mathrm{~m}$ deep, with transparent waters, occupying the waterfalls in rocky areas, and unconsolidated bottom over sandy, pebbles or gravel areas at the edge of the waterfall.

Etymology. The name refers to the rio Cricaré, where type locality of this fish is found, and is used as a Latinized geographic adjective.

Conservation status. Characidium cricarense occurs in coastal basins from Northeastern Mata Atlântica ecoregion (sensu Abell et al., 2008) along three Brazilian states: Bahia, Espírito Santo and Minas Gerais. The species inhabits turbulent waters in rapids, occupying the rocky areas as well as the unconsolidated bottom near the rapids. Even though a mining disaster occurred in Doce basin, where Characidium cricarense might occur, no specific threats to the species is detected in the whole area of distribution. Consequently, the conservation status of Characidium cricarense may be classified as Least Concern (LC), according to the International Union for Conservation of Nature (IUCN) categories and criteria (IUCN, 2017).

\section{Discussion}

Characidium cricarense is a member of the group of species without scales in the area of the isthmus. All species of Clade $\mathrm{C} 1$, and some of its immediate outgroups, have unscaled isthmus (Buckup, 1993a). Among species without scales in the isthmus, $C$. cricarense shares a large distance from the anus to the anal-fin origin $(>10 \% \mathrm{SL})$. This character is restricted to a small group of congeners, which includes Characidium alipioi, C. cricarense, C. kamakan, and C. hasemani.

Characidium alipioi, C. cricarense and C. kamakan are distributed in Atlantic rainforest coastal streams between the Pardo drainage in Bahia and the São João drainage in Rio de Janeiro (Leitão, Buckup, 2014; Zanata, Camelier, 2015). These species are morphologically similar, and have similar pigmentation patterns, including a B-shaped set of caudal bands, and the clearer area in front of the main dark band of dorsal fin. Although a formal phylogenetic analysis was not carried out herein, the combination of characteristics that include the pigmentation pattern, unscaled isthmus but scaled chest, and long distance from the anus to the anal-fin origin with little imbricated, aligned scales, might diagnose a putative species clade that we call the $C$. alipioi species group. The number of species of the $C$. alipioi group may increase in the future, because recent studies (Serrano et al., 2019) have demonstrated the presence of cryptic species in the Paraíba do Sul drainage that are morphologically similar 


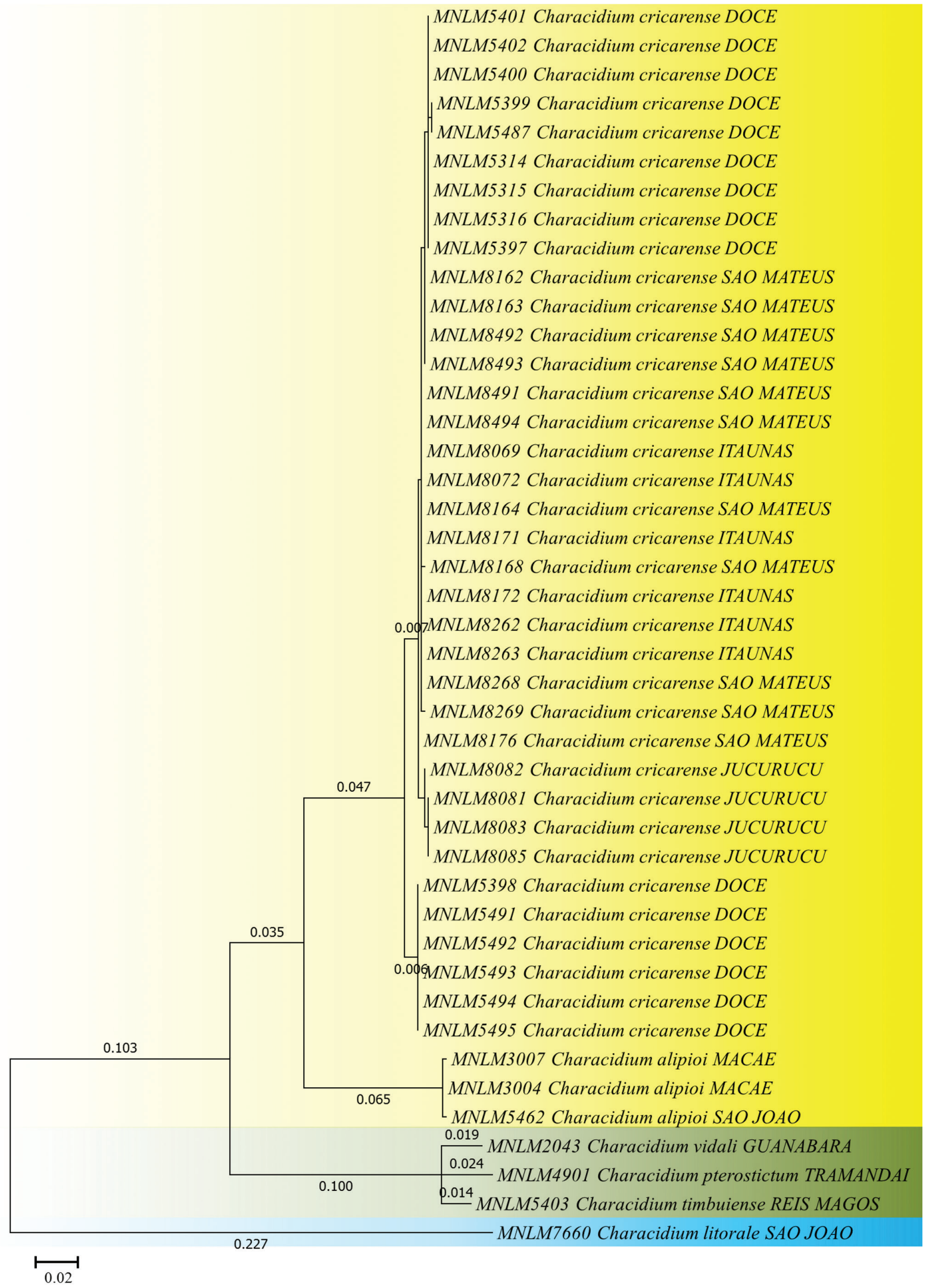

Fig. 2. Phylogenetic tree based on molecular data, generated with the maximum likelihood method and $\mathrm{HKY}+\mathrm{G}$ model. MNLM codes and associated data are listed in Tab. 1. River basins are indicated next to species names. Divergence values are indicated along the branches, except for those below $0.5 \%$ which were suppressed. Characidium alipioi species group represented in yellow, Characidium grajahuense species group in green, and C. litorale (outgroup) in blue. 


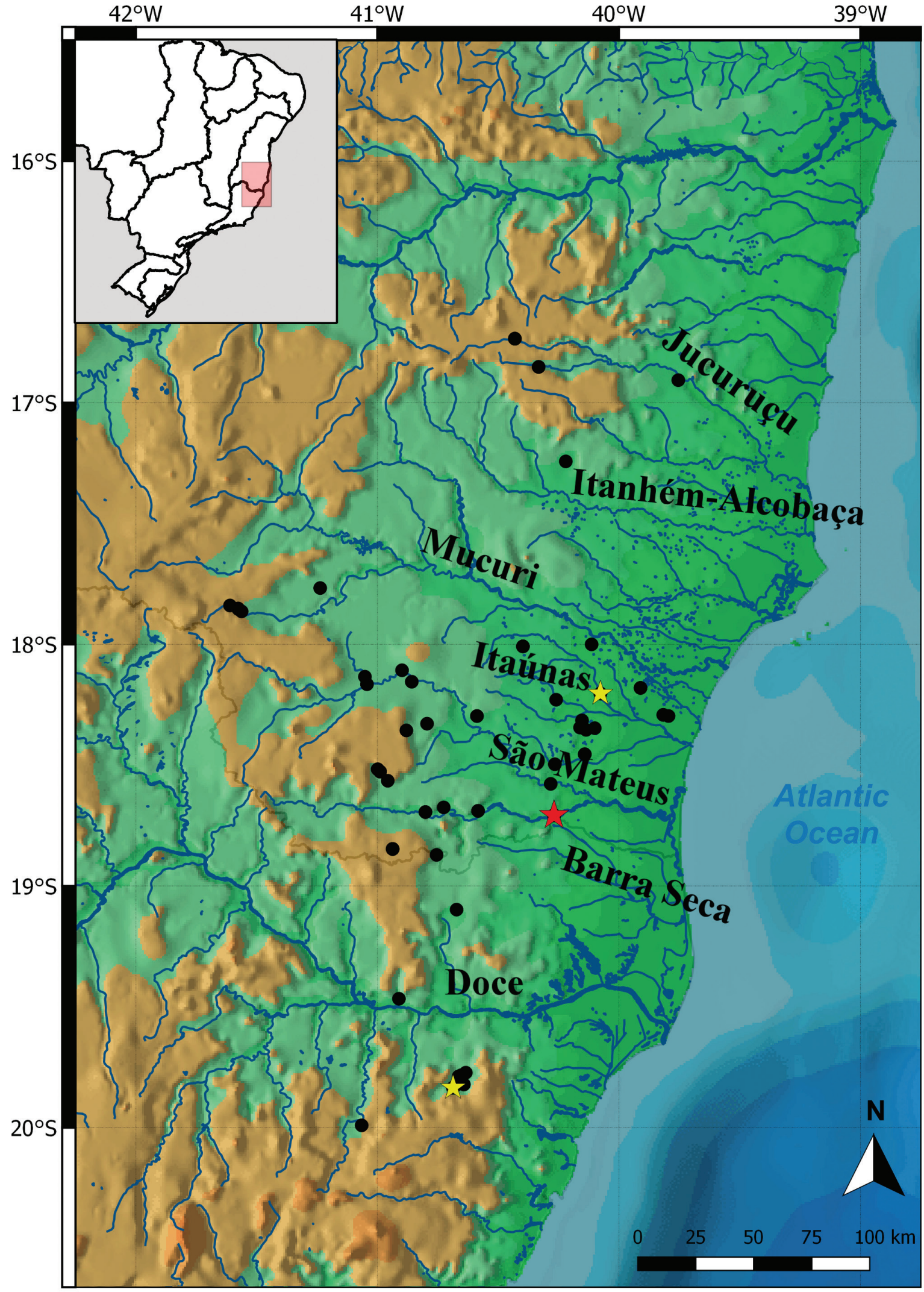

Fig. 3. Map of eastern South America showing Characidium cricarense distribution: the red star indicates the type locality, yellow stars indicate localities collection of paratypes, and black dots represent localities collection of non-type specimens. The National Hydrographic Division (CNRH 2003) is represented in thick black lines on highlighted map; red-shaded area represents the main map, at the edge of East Atlantic and Southeast Atlantic basins. 


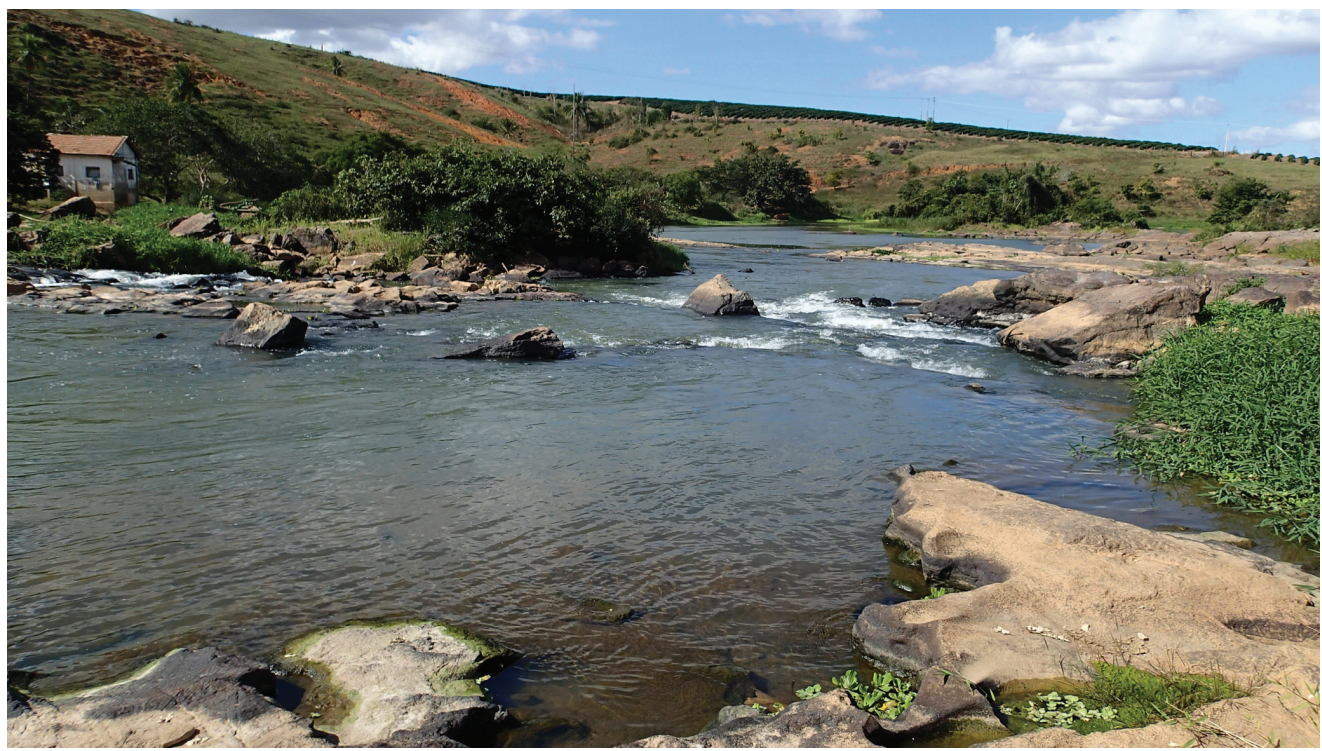

Fig. 4. Fast flowing stream, type locality of Characidium cricarense, at Cachoeira do Inferno rapids in rio Cricaré, São Mateus, ES, Brazil. GPS coordinates: $18^{\circ} 42^{\prime} 24.5^{\prime \prime} \mathrm{S} 40^{\circ} 16^{\prime} 7.2^{\prime \prime} \mathrm{W}$.

Tab. 3. Average of body depth (as \% of SL) for species of Characidium alipioi group. Ranges of values are indicated in parentheses.

\begin{tabular}{lccc}
\hline Body depth at: & C. alipioi & C. cricarense & C. kamakan \\
\hline 7-7' - Dorsal-fin origin & $17.7(16.9-18.5)$ & $18.3(16.3-20.0)$ & $21.3(20.6-21.8)$ \\
13-13' - Anal-fin origin & $14.5(13.6-15.2)$ & $13.9(13.0-15.5)$ & $17.4(16.6-17.8)$ \\
19-19' - Caudal peduncle & $10.5(10.1-11.3)$ & $9.8(8.8-10.5)$ & $12.6(12.0-12.9)$ \\
\hline
\end{tabular}

to C. alipioi. Characidium hasemani is distributed in northern Brazil and Guyana (Fricke et al., 2019), and has very distinct pigmentation pattern, including double dark bands in caudal fin and the middle band in the dorsal fin reaching its anteriormost margin. Further research is required to evaluate the hypothesis of close phylogenetic relationship between $C$. hasemani and the C. alipioi species group.

Among members of the C. alipioi group, $C$. cricarense may be distinguished from C. kamakan by the smaller depth of the body at all three body depth landmarks (Tab. 3). Adults of C. kamakan may be diagnosed by the conspicuous reticulated pattern formed by patches of pigment in the scales (Zanata, Camelier, 2015), but this reticulate pattern may be absent in younger specimens. C. cricarense may be distinguished from C. alipioi by the smaller number of scales between the lateral line and the predorsal series ( $4 v$ s. 5 series in C. alipioi). A few specimens of $C$. cricarense have five dorsolateral series of scales above the lateral line, but this count is by far infrequent among examined specimens. Additionally, C. cricarense has a greater distance, and 1 or 2 additional scales between the anus and anal-fin origin than C. alipioi.

Characidium cricarense occurs in six separate coastal drainages: rio Jucuruçu, rio Itanhém-Alcobaça, rio Mucuri, rio Itaúnas, rio São Mateus and lower part of rio Doce. The low morphologic and genetic divergence among these isolated populations is congruent with a geologically recent common origin. Considering that currently there is no direct freshwater connection between these drainages, and that during the Last Glacial Maximum (LGM) the sea level was at about 130 meters below the present baseline (Mahiques et al., 2010; Lambeck et al., 2014), it is hypothesized that there was some connectivity between the six basins, perhaps through deltaic areas that extended over the continental shelf, which was exposed between southern Bahia and northern Espírito Santo during the LGM. This hypothesis is corroborated by the wide expanse of the continental shelf in this area, forming the so called Abrolhos Bank, and the existence of northwardly directed paleochannels of a delta development from the rio Doce, which extended the river mouth to approximately $50 \mathrm{~km}$ to the north of the modern one (Dominguez et al., 1987; Rossetti et al., 2015). The fluvial erosion of the Barreiras Formation in southern Bahia carved valleys during epochs of lower sea level (Bittencourt et al., 1979). Subsequent submersion of the continental platform has produced the current isolation of these valleys, which represent headwaters of formerly larger river basins. Additionally, the recent transgressive phase of sea level fluctuation formed drowned lakes (e.g. Lagoa de Juparanã) and lowlands around the lower Doce basin. These lakes and lowlands may have facilitated freshwater connectivity to the São Mateus basin. We have not detected the presence of C. cricarense in the rio Peruípe basin. This basin is located between the rio Itanhém-Alcobaça and the rio Mucuri basins. The lack of records in the rio Peruípe basin may be due to poor sampling efforts, and further research is required to confirm the apparent absence of $C$. cricarense in that basin. 
The DNA barcode sequences revealed only minor divergence (less than $1 \%$ ) among the various populations of $C$. cricarense. The largest haplotype divergence was recorded in the rio Doce basin, which has two main lineages of mitochondrial haplotypes (Fig. 2). The genetic divergence, however, is well below the accepted level of $2 \%$ divergence within conspecific lineages (Pereira et al., 2013), and we were not able to identify significant morphologic variation among specimens of rio Santa Maria do Rio Doce drainage and other tributaries of rio Doce.

The DNA barcode similarity between $C$. cricarense and C. alipioi corroborates our hypothesis that the species with a large distance between the anus and the anal-fin origin comprise a group of species (Fig. 2). The sister group of the C. alipioi species group is comprised by the $C$. grajahuense species group, which is represented in our analysis by specimens of C. pterostictum, C. timbuiense and C. vidali. In our maximum likelihood analysis (Fig. 2), the branches from the common ancestor of $C$. cricarense and C. alipioi correspond to $4.7 \%$ and $6.5 \%$, respectively, of corrected nucleotide divergence. These values are substantially smaller than the $8.8 \%$ and $10.0 \%$ of anagenetic change along the lineages comprising gap between the C. alipioi and $C$. grajahuense species groups. These values are well above the $2 \%$ cutoff value of genetic barcode distance usually accepted for species-level divergence (Pereira et al., 2013), and corroborate our hypothesis that the $C$. grajahuense and the C. alipioi groups constitute distinct lineages among species with unscaled isthmus in southeastern Brazil.

Comparative material examined. All specimens listed below are from Brazil. Locality information have been abbreviated to include only the municipality, state abbreviation, and name of main river.Characidium alipioi: MNRJ 5550, 1 (holotype), $51.9 \mathrm{~mm}$ SL; MNRJ 5551, 1 (paratype), 52.0 mm SL; MNRJ 5552, 1 (paratype), $49.4 \mathrm{~mm} \mathrm{SL}$; MNRJ 5553, 1 (paratype), $45.9 \mathrm{~mm} \mathrm{SL}$; MNRJ 5554, 1 (paratype), $45.5 \mathrm{~mm} \mathrm{SL}$, Carmo, RJ, rio Paraíba do Sul; MNRJ 39301, 12, 52.8-53.0 mm SL, Macaé, RJ, rio do Ouro; MNRJ 50828, 1, 37.6 mm SL, Casimiro de Abreu, RJ, rio Aldeia Velha; MNRJ 50986, 14, 50.7-69.1 mm SL, Cachoeiro de Itapemirim, ES, rio Itapemirim; MNRJ 50997, 4, $52.1 \mathrm{~mm} \mathrm{SL}$, Conceição de Macabu, RJ, tributary of rio Macaé. Characidium bahiense: MNRJ 22410, 14, 21.1-21.3 mm SL, Arembepe, BA, rio Capivara. Characidium fasciatum: MBML 7969, 4, 30.9-48.1 mm SL, Guarda Mor, MG, ribeirão das Traíras; MNRJ 31787, 1, 61.5 mm SL, Piumhi, MG, Ribeirão da Cachoeira. Characidium gomesi: MNRJ 31871, 3, 39.8-44.8 mm SL, Carandaí, MG, rio Carandaí. Characidium grajahuense: MNRJ 41173, 3, 76.4-82.1 mm SL, Rio de Janeiro, RJ, Mendanha waterfall. Characidium hasemani: MBML 8675, 3, 38.0-42.5 mm SL, Paranatinga, MT, rio Culuene; MNRJ 33255, 2, 47.3-55.4 mm SL, Itaituba, PA, rio Itapacurazinho. Characidium helmeri: MBML 531, 18, 27.8-36.0 mm SL, Trancoso, BA, rio Trancoso; MNRJ 50929, 8, 17.0-25.5 mm SL, Prado, BA, tributary of rio Cahy. Characidium interruptum: MNRJ 38991, 6, 33.4-36.3 mm
SL, Piabeta, RJ, tributary of rio Inhomirim. Characidium japuhybense: MNRJ 43512, 3, 50.8-60.0 mm SL, Angra dos Reis, RJ, rio Roncador. Characidium kamakan: MNRJ 22419, 16, 39.8-50.1 mm SL, Cândido Sales, MG, rio Pardo; MNRJ 42132, 4 (paratypes), 42.4-49.0 mm SL, Camacan, BA, rio Panelão. Characidium lanei: MNRJ 33040, 33, 29.8-33.2 mm SL, Pariquera Açu, SP, tributary of rio Ribeira do Iguape; MNRJ 39277, 3, 29.4-37.7 mm SL, Bertioga, SP, tributary of rio Itapanhaú. Characidium lauroi: MNRJ 47260, 3, 59.9-62.1 mm SL, Rio Claro, RJ, rio das Pedras. Characidium litorale: MNRJ 51016, 3, 37.2-43.7 mm SL, Conceição de Macabu, RJ, tributary of rio Macaé. Characidium oiticicai: MNRJ 38939, 2, 48.0-55.5 mm SL, Ubatuba, SP, tributary of rio Grande. Characidium pterostictum: MNRJ 39508, 31, 40.7-43.0 mm SL, Iporanga, SP, rio Betari; MNRJ 41094, 17, 57.3-71.1 mm SL, Ubatuba, RS, tributary of rio Grande. Characidium schubarti: MNRJ 39640, 3, 36.1-56.4 mm SL, Capão Bonito, SP, at Abaitinga district on road SP-139 km 81. Characidium sp: MBML 1327, 3, 32.6-43.8 mm SL, Muniz Freire, ES, córrego Rico em Menino Jesus; MBML 3836, 5, 30.2-42.6 mm SL, Itamaraju-BA, tributary of rio Jucuruçu; MBML 3837, 3, 39.7-48.8 mm SL, Jucuruçu, BA, rio Jucuruçu; MBML 5146, 1, 21.8 mm SL, Sooretama, ES, córrego Paraisópolis; MBML 5911, 3, 44.0-48.4 mm SL, Muniz Freire, ES, rio Pardo; MNRJ 37713, 1, 37.9 mm SL, Boa Esperança, ES, rio Cotaxé; MNRJ 50843, 1, 28.7 mm SL, Águia Branca, ES, rio Braço Sul; MNRJ 50844, 2, 37.1-37.4 mm SL, Baixo Guandu, ES, rio Mutum. Characidium timbuiense: MNRJ 39150, 4, 33.5-51.6 mm SL, Santa Maria de Jetiba, ES, rio Taquarinha da Penha; MNRJ 41900, 30, 42.4$56.6 \mathrm{~mm}$ SL, Santa Teresa, ES, rio Valsugana Velha. Characidium vidali: MNRJ 40284, 56, 33.9-61.0 mm SL, Guapimirim-RJ, rio Soberbo; MNRJ 51017, 7, 43.0-59.1 mm SL, Conceição de Macabu, RJ, tributary of rio Macaé.

\section{Acknowledgments}

This project received support from $\mathrm{CNPq}$ grants to EM (proc. 301038/2017-1), to LMSS (proc. 302248/2016-1), to LFSI (proc. 350672/2011-3), to PAB (proc. 476822/2012-2, 440566/2015-0, 312801/2017-1, 423526/2018-9); CAPES/ CNPq Protax grant to ACGSM (proc. 440566/2015-0); CAPES grant to LFSI (PROFIX Post-doctoral fellowship); and FAPES grant to MMS (proc. 74026224/2016), LFSI (procs. 53132203/2011, 68856598/2014, and TO 83/2018). Collecting activities were performed under license nrs. 8939-1 to PAB, and 32736-3 and 48489-4 to LFSI, issued by the Instituto Permanente de Conservação da Biodiversidade. We are grateful to the Genomic Platform - DNA Sequencing - RPT01A (Rede de Plataformas Tecnológicas FIOCRUZ). We thank Carla C. D. Quijada, Cristiana A. S. do Nascimento, Cristiano R. Moreira, Décio F. Moraes Junior, Emanuel Neuhaus, Giovana Vignoli, Gustavo A. Ferraro, Ingrid M. Mazzini, Juliana P. da Silva, Lorena Tonini, Luiz F. Duboc, Marcelo R. de Britto, Maria C. S. Mendonça, Natane Sartor, Priscila Plesley, Ronaldo F. Martins-Pinheiro, Tatyana Gomes, Victor de Brito, and Willian B. Jennings for all the help during field and laboratory activities. 


\section{References}

Abell R, Thieme ML, Revenga C, Bryer M, Kottelat M, Bogutskaya $\mathrm{N}$, et al. Freshwater ecoregions of the world: a new map of biogeographic units for freshwater biodiversity conservation. Bioscience. 2008; 58(5):403-14.

Bittencourt ACSP, Martin L, Vilas Boas GS, Flexor JM. Quaternary marine formations of the coast of the State of Bahia (Brazil). Proceedings of the 1978 International Symposium on Coastal Evolution in the Quaternary. São Paulo: Instituto de Geociências - USP; 1979. p.232-253.

Buckup PA. Redescription of Characidium fasciatum, type species of the Characidiinae (Teleostei, Characiformes). Copeia. 1992; 1992(4):1066-73.

Buckup PA. Phylogenetic interrelationships and reductive evolution in Neotropical Characidiin fishes (Characiformes, Ostariophysi). Cladistics. 1993a; 9(3):305-41.

Buckup PA. Review of the characidiin fishes (Teleostei: Characiformes), with descriptions of four new genera and ten new species. Ichthyol Explor Freshwaters. 1993b;4(2):97-154.

CNRH. Resolução no. 32, de 15 de Outubro de 2003. Ministério do Meio Ambiente. Conselho Nacional de Rescursos Hídricos Brazil [Internet]. 2003. Available from: http://www.cnrh.gov. br/index.php?option $=$ com content\&view $=$ article\&id $=14$

Dominguez JML, Martin L, Bittencourt ACSP. Sea-level history and Quaternary evolution of river mouth-associated beachridge plains along the east-southeast Brazilian coast: a summary. In: Nummedal D, Pilkey OH, Howard JD, editors. Sea-Level Fluctuation and Coastal Evolution. SEPM Society for Sedimentary Geology; 1987. p.115-127.

Fricke R, Eschmeyer WN, Laan R van der, editors. Eschmeyer's Catalog of Fishes: Genera, Species, References [Internet]. 2019. Available from: http://researcharchive.calacademy.org/ research/ichthyology/catalog/fishcatmain.asp

Handy SM, Deeds JR, Ivanova NV, Hebert PDN, Hanner RH, Ormos A, et al. A single-laboratory validated method for the generation of DNA barcodes for the identification of fish for regulatory compliance. J AOAC Int. 2011; 94(1):201-10.

Hebert PDN, Cywinska A, Ball SL, deWaard JR. Biological identifications through DNA barcodes. Proc R Soc Lond B. 2003; 270(1512):313-21.

International Union for Conservation of Nature (IUCN). Standards and Petitions Subcommittee. Guidelines for using the IUCN Red List Categories and Criteria. Version 13 [Internet]. 2017 [accessed 2018 July]. Available from: http://www.iucnredlist. org/documents/RedListGuidelines.pdf

Jennings WB. Phylogenomic data acquisition: principles and practice. New York, London, Boca Raton: CRC Press/Taylor \& Francis; 2016.

Jennings WB, Ruschi PA, Ferraro G, Quijada CC, Silva-Malanski ACG, Prosdocimi F, et al. Barcoding the Neotropical freshwater fish fauna using a new pair of universal COI primers with a discussion of primer dimers and M13 primer tails. Genome. 2019; 62(2):77-83.

Kumar S, Stecher G, Tamura K. MEGA7: Molecular Evolutionary Genetics Analysis Version 7.0 for bigger datasets. Mol Biol Evol. 2016; 33(7):1870-74.

Lambeck K, Rouby H, Purcell A, Sun Y, Sambridge M. Sea level and global ice volumes from the Last Glacial Maximum to the Holocene. Proc Natl Acad Sci. 2014; 111(43):15296-303.

Leitão RP, Buckup PA. A new species of Characidium (Characiformes: Crenuchidae) from coastal basins of Serra do Mar, Southeastern Brazil. Copeia. 2014; 2014(1):14-22.

Lis JT. Fractionation of DNA fragments by polyethylene glycol induced precipitation. Methods Enzymol. 1980; 65(1):347-53.
Mahiques MM, Sousa SHM, Furtado VV, Tessler MG, Toledo FAL, Burone L, et al. The Southern Brazilian shelf: General characteristics, quaternary evolution and sediment distribution. Braz J Oceanogr. 2010; 58(2):25-34.

Melo MRS, Buckup PA. Characidium stigmosum (Characiformes: Crenuchidae): a new species of Characidiin fish from Central Brazil. Copeia. 2002; 2002(4):988-93.

Melo MRS, Oyakawa OT. A new species of Characidium Reinhardt (Characiformes, Crenuchidae) with a distinctively dimorphic male. Copeia. 2015; 103(2):281-89.

Miller SA, Dykes DD, Polesky HF. A simple salting out procedure for extracting DNA from human nucleated cells. Nucleic Acids Res. 1988; 16(3):1215. Available from: https://doi.org/10.1093/ nar/16.3.1215

Otto TD, Vasconcellos EA, Gomes LHF, Moreira AS, Degrave WM, Mendonca-Lima L, et al. ChromaPipe: a pipeline for analysis, quality control and management for a DNA sequencing facility. Genet Mol Res. 2008; 7(3):861-71.

Pereira LHG, Hanner R, Foresti F, Oliveira C. Can DNA barcoding accurately discriminate megadiverse Neotropical freshwater fish fauna? BMC Genet. 2013; 14(1):20. Available from: https://doi.org/10.1186/1471-2156-14-20

Posada D. jModelTest: Phylogenetic model averaging. Mol Biol Evol. 2008; 25(7):1253-56.

Ratnasingham S, Hebert PDN. BOLD: The Barcode of Life Data System (www.barcodinglife.org). Mol Ecol Notes. 2007; 7(3):355-64

Ratnasingham S, Hebert PDN. A DNA-based registry for all animal species: The Barcode Index Number (BIN) System. PLoS One. 2013; 8(8):e66213. Available from: https://doi.org/10.1371/ journal.pone.0066213

Rossetti DF, Polizel SP, Cohen MCL, Pessenda LCR. Late Pleistocene-Holocene evolution of the Doce River delta, southeastern Brazil: implications for the understanding of wave-influenced deltas. Mar Geol. 2015; 367:171-90.

Sanger F, Nicklen S, Coulson AR. DNA sequencing with chain-terminating inhibitors. Proc Natl Acad Sci. 1977; 74(12):5463-67.

Sarmento-Soares LM, Martins-Pinheiro RF. A fauna de peixes nas bacias do sul do Espírito Santo, Brasil. Sitientibus ser Ci Biol. $2013 ; 13: 1-37$.

Serrano ÉAEA, Melo BF, Freitas-Souza D, Oliveira MLM, Utsunomia R, Oliveira $\mathrm{C}$, et al. Species delimitation in Neotropical fishes of the genus Characidium (Teleostei, Characiformes). Zool Scr. 2019; 48(1):69-80.

Taylor WR, Van Dyke GC. Revised procedures for staining and clearing small fishes and other vertebrates for bone and cartilage study. Cybium. 1985; 9(2):107-19.

Ward RD, Zemlak TS, Innes BH, Last PR, Hebert PDN. DNA barcoding Australia's fish species. Phil Trans R Soc B. 2005; 360(1462):1847-57.

Weitzman SH. The osteology of Brycon meeki, a generalized characid fish, with an osteological definition of the family. Stanford Ichthyol Bull. 1962; 8(1):1-77.

Zanata AM, Camelier P. Two new species of Characidium Reinhardt (Characiformes: Crenuchidae) from northeastern Brazilian coastal drainages. Neotrop Ichthyol. 2015; 13(3):487-98.

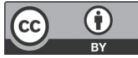

Submitted September 12, 2018 Accepted June 10, 2019 by George Mattox 